\title{
Editorial
}

\section{Regulation of food marketing to children: are statutory or industry self-governed systems effective?}

Extensive marketing of foods and drinks that are high in fat, sugar and sodium (HFSS) directly targeted to young people has contributed to the rapid rise in youth with obesity and increased lifetime risk for diseases such as diabetes, hypertension and cancer ${ }^{(1)}$. Yet real progress towards tackling this problem has been slow ${ }^{(2)}$ and questions remain over the most appropriate and efficacious measures. This discussion often focuses on the relative merits of industry-initiated improvements $v$. statutory restrictions ${ }^{(3,4)}$. However, research has demonstrated limitations to both approaches, with similar types of loopholes that allow food marketers to continue to surround children with highly effective messages promoting HFSS products, including fast-food restaurants, sugary drinks, candy, snacks and sugary cereals.

Transnational industry stakeholders (e.g. food and beverage manufacturers) have acknowledged the potential harm of unhealthy food marketing and their role in addressing childhood obesity by enacting self-regulatory actions in major markets worldwide, typically in the form of multi-company pledges to advertise only nutritious options directly to children ${ }^{(5)}$. In most countries, governments have ceded the responsibility for improving marketing to children to these self-regulatory programmes ${ }^{(6)}$. Although industry self-regulation could, in principle, help decrease children's exposure, independent evaluations have demonstrated limited improvements in the nutritional quality of foods and beverages marketed to children or reductions in children's exposure to marketing of HFSS foods following implementation of food industry self-regulation ${ }^{(7)}$. For example, the Children's Food and Beverage Advertising Initiative (CFBAI) was launched in the USA in 2006. As of 2016, eighteen of the largest food and beverage manufacturers and fast-food restaurants have pledged to 'encourage healthier dietary choices' in advertising directed to children under 12 years of age ${ }^{(8)}$. However, children in 2015 saw just $3 \%$ fewer food ads on television than they had in 2007, the first year that children's exposure to food ads was lower than it had been before the CFBAI was implemented ${ }^{(9)}$. Furthermore, $86 \%$ of food ads viewed by children promoted HFSS products in 2009 compared with $94 \%$ before companies enacted their CFBAI pledges ${ }^{(10)}$. In addition, the nutritional quality of products advertised on children's television remains worse than those advertised during programming for older audiences ${ }^{(11)}$.

As a result, improvements in food marketing to children associated with industry self-regulation have been small and slow. In addition, there are obvious limitations to relying on industry to voluntarily make substantial changes to successful business models. Accordingly, public health experts have argued that government regulatory or legislative statutory actions will be the only effective solution $^{(4,12)}$. The WHO has given a mandate to act, via Resolution WHA63.14 (endorsed in May 2010), and has provided specific policy and technical guidance ${ }^{(13,14)}$.

In 2007, the UK was the first country to introduce statutory legislation specifically addressing food marketing to children, with the stated aim of 'limiting the exposure of children to HFSS (foods high in fat, sugar, and/or salt) advertising on television, as a means of reducing opportunities to persuade children to demand and consume HFSS products $^{(15)}$ (p. 3). HFSS advertising (determined by nutrient profiling) was banned in and around programmes of particular appeal to children under 16 years of age, with additional 'content rules' prohibiting the use of some promotional characters among other components. Although the UK broadcast regulator reported that children saw $34 \%$ less HFSS advertising following the regulations ${ }^{(16)}$, academic evaluations suggest that reductions in exposure are likely limited to dedicated children's programming ${ }^{(17)}$ or have not occurred at all - indeed, increases in relative exposure to HFSS advertising were found ${ }^{(18)}$. Furthermore, fast-food restaurants have increased marketing of 'healthier' options that meet the nutrition criteria but allow restaurants to continue to market their brand to children ${ }^{(19)}$. It remains to be seen whether brand advertising (ads that do not depict foods at all) for other types of products has also increased over this period, another potential loophole for circumventing the regulations.

Few other statutory approaches have been evaluated. The Mexican Government introduced regulations in 2015 to limit unhealthy food advertising to children on television. However, these regulations are not expected to lead to substantial improvements in children's exposure to unhealthy food advertising in Mexico due to two significant limitations. The nutrition quality standards in the Mexican regulations are weaker than the UK standards and the regulations do not address advertising for HFSS foods during the majority of television programming that children view ${ }^{(20)}$.

\section{Criteria for successful regulation}

The WHO has identified three critical concepts that must be defined when crafting regulations concerning food marketing to children to help address the limited 
improvements resulting from both self-regulatory and statutory actions ${ }^{(14)}$.

1. The nutrition criteria used to identify 'unbealthy' foods and drinks that cannot be advertised to children

The UK approach - a nutrition profiling model, developed independently of the food industry and validated by nutrition professionals - has been successful at eliminating marketing of HFSS foods during child-directed programming. WHO Europe has also developed a nutrient profile model in collaboration with seventeen countries across the region; in-country pilot testing found the model to be appropriate and suitably strict ${ }^{(21)}$. In contrast, industry self-regulatory approaches have focused on reducing sugar, fat and/or sodium to amounts that vary by product category ${ }^{(5,22)}$, resulting in products marketed to children as 'healthier' choices that contain lower, but not low, levels of sugar, fat and/or salt and that may not provide any nutritional benefits at all. For example, CFBAI has established 'category-specific uniform nutrition criteria', whereby for each of ten categories maximum energy and nutrients to limit (saturated fat, sodium, sugar) are specified as well as some nutrients to be encouraged (e.g. whole grains, fortification with vitamins) ${ }^{(8)}$.

\section{The age range for 'children' who should be protected from unbealthy food marketing}

Industry self-regulatory pledges all define children as individuals 11 years old or younger ${ }^{(6)}$. In contrast, the UK legislation defines children as youth under 16 years, while the UN defines a child as an individual under age 18 years $^{(23)}$.

3. Types of marketing, including what qualifies as 'childdirected', that may not be used to promote HFSS foods and drinks

Various approaches have been used to identify childdirected marketing. In Quebec, regulation of 'child-directed' marketing bans advertising of products 'exclusively designed for children or particularly appeal to children, when children consist of $15 \%$ or more of the total audience $^{\text {(24) }}$. Government and industry regulations in the UK and USA respectively have focused on limiting television food advertising during programming where children are the primary audience, i.e. the proportion of children in the viewing audience is above a certain threshold. In the UK, the rules cover programmes in which the proportion of children (4-15 years) in the audience is at least 20\% higher than would be found in the general population ${ }^{(15)}$. Most participating companies in the US CFBAI define child-directed programming as those where children (2-11 years) make up at least $35 \%$ of the total audience. Both definitions have led to increases in advertising exposure during other types of television programming that are widely viewed by children, such as family programming. Many in the UK have called for the use of a 9 p.m. 'watershed' system instead, such that HFSS advertising would be restricted during viewing times popular with children similar to restrictions on other adultonly content (e.g. programming with violence or depictions of sex ${ }^{(25)}$. In the USA, a national panel of experts recommended that advertising in media and other venues where children (2-14 years) make up $25 \%$ or more of the audience, as well as the use of marketing strategies, techniques, characteristics and venues suggesting that children are the target demographic, be considered childdirected marketing and covered by CFBAI pledges ${ }^{(26)}$.

Furthermore, if regulating television advertising to children has been problematic, it now appears relatively straightforward in comparison to the complexities facing policy making aiming to address digital marketing, such as social media, mobile apps and games. US studies have demonstrated the omnipresence of unhealthy food marketing on food company websites used by over a million children each month and the detrimental effect of 'advergames' on children's snack consumption ${ }^{(27)}$.

\section{Future directions}

In the USA, public health experts have attempted to engage the food industry to address these limitations in self-regulation of food marketing to children through voluntary actions. In 2011, a US government inter-agency working group proposed several principles for responsible food marketing to children that would support rather than undermine children's health, including that foods marketed to children should contain a meaningful amount of nutrients that are beneficial for children (e.g. fruit, vegetables or whole grains); that regulations should limit marketing to children up to age 17 years; and that all forms of marketing to children (including in schools, character and toy co-branding, and product placements) should be covered $^{(28)}$. However, the food industry successfully lobbied against these 'voluntary guidelines' and they were never issued despite overwhelming positive support during the comment period ${ }^{(29)}$. More recently a national panel of experts developed specific definitions of responsible food marketing to children for companies to adopt, including defining children as up to age 14 years and refining definitions of 'child-directed' marketing to include media disproportionately viewed by children, venues that children are more likely to frequent (e.g. community recreation centres) and techniques that specifically appeal to children ${ }^{(26)}$. To date, the CFBAI and major food companies have not agreed to any of these proposed improvements in food industry self-regulation.

Recent government actions to strengthen statutory regulations regarding food marketing to children have had somewhat more success. A UK Government inquiry into childhood obesity recommended tougher controls on the marketing of unhealthy foods and drinks, including 
the implementation of a 9 p.m. watershed to ensure that regulations apply to the programmes that children are likely to watch, not just to children's specific programming ${ }^{(30)}$, although such changes did not appear in the subsequent childhood obesity plan ${ }^{(25)}$. In late 2016, the UK's Committee on Advertising Practice announced new rules regarding HFSS advertising within non-broadcast media, intended to bring the regulations more in line with those that govern television advertising from July $2017^{(31)}$. In 2015, Chile significantly strengthened its law regarding the nutritional composition of food and advertising to restrict all forms of food advertising aimed at children under 14 years, regardless of where it occurs $^{(32)}$. The law also specifies that features of the advertisements, such as licensed characters, animation, toys, children's settings and child voices, indicate that advertising is aimed at children and must comply with nutrition standards. Furthermore, Canadian Prime Minister Trudeau in 2016 mandated that the Minister of Health introduce 'new restrictions on the commercial marketing of unhealthy food and beverages to children' as a top priority $^{(33)}$.

Despite consensus on the need for regulations to limit HFSS marketing to children, many questions remain over the most successful actions and measures that can be taken to reduce the extent, exposure and negative impact of such marketing. As noted, there is evidence that statutory regulation can be effective (although close attention must be paid to the specifics and comprehensiveness of the legislation) but studies show that the impact of self-regulation is more variable. Hybrid co-regulatory or quasi-regulatory approaches have also been adopted for front-of-pack food labelling in some regions whereby national authorities are responsible for encouraging best practices and endorsing particular developments ${ }^{(34,35)}$. These approaches have not been used to regulate food marketing and there is limited evidence of effectiveness in other domains, but they could be considered. For example, a third party or regulatory agency would verify industry-developed codes or a government would require statutory regulation if certain goals are not reached by stakeholders within a specified time frame.

The main difficulty with comprehensive statutory regulation across media platforms and with hybrid approaches lies in implementation. They both require political will as well as a regulatory framework that allows for them, and neither is the case in the USA at present. However, there is evidence of progress on statutory regulations. Canada and Chile are currently progressing with plans for comprehensive marketing bans. Specifically, implementation of Chile's new law would see a ban on all 'high in' food marketing on television and cinema between 6 a.m. and 10 p.m. (a notable improvement on current laws) ${ }^{(36)}$ and Canada is considering a ban on all commercial marketing to children aged 16 years or under in line with the 2014 Ottawa Principles ${ }^{(37)}$.
Regardless of approach, regular independent monitoring of the food industry is essential and it is notable that, both in the USA and UK, there is an active advocacy community and robust academic research being conducted to ensure that food marketing does not simply slip under the radar. Good-quality evidence - of marketing impact and evaluation of regulatory approaches - is essential to drive political will for change. Additional research on the impact of unhealthy food marketing on children aged 12 years or older, as well as the impact of marketing beyond television advertising, would provide critical support for expanding protections provided by both statutory and industryinitiated regulations. With current rates of childhood obesity and the dire consequences for children's health, there is no room to be complacent.

$$
\begin{array}{r}
\text { Emma J Boyland }{ }^{1} \text { and Jennifer L Harris }{ }^{2} \\
{ }^{1} \text { Department of Psychological Sciences } \\
\text { University of Liverpool } \\
\text { Eleanor Rathborne Building } \\
\text { Bedford Street South } \\
\text { Liverpool, L69 7ZA, UK }
\end{array}
$$

${ }^{2}$ Rudd Center for Food Policy \& Obesity University of Connecticut One Constitution Plaza, Suite 600 Hartford, CT 06103, United States Email: jennifer.harris@uconn.edu

\section{References}

1. World Health Organization (2016) Consideration of the evidence on childhood obesity for the Commission on Ending Childhood Obesity. http://apps.who.int/iris/ bitstream/10665/206549/1/9789241565332_eng.pdf?ua=1 (accessed February 2017).

2. Kraak VI, Vandevijvere S, Sacks G et al. (2016) Progress achieved in restricting the marketing of high-fat, sugary and salty food and beverage products to children. Bull World Health Organ 94, 540-548.

3. Chambers SA, Freeman R, Anderson AS et al. (2015) Reducing the volume, exposure and negative impacts of advertising for foods high in fat, sugar and salt to children: a systematic review of the evidence from statutory and self-regulatory actions and educational measures. Prev Med 75, 32-43.

4. Mehta K (2010) Statutory restriction on unhealthy food marketing to children: the debate continues. Public Health Nutr 13, 1001-1002

5. Hawkes C \& Harris JL (2011) An analysis of the content of food industry pledges on marketing to children. Public Health Nutr 14, 1403-1414.

6. Hawkes C \& Lobstein T (2011) Regulating the commercial promotion of food to children: a survey of actions worldwide. Int J Pediatr Obes 97, 1962-1973.

7. Kraak VI, Story M, Wartella EA et al. (2011) Industry progress to market a healthful diet to American children and adolescents. Am J Prev Med 41, 322-333. 
8. Council of Better Business Bureaus (2016) Children's Food and Beverage Advertising Initiative. About the Initiative. http://www.bbb.org/council/the-national-partner-program/ national-advertising-review-services/childrens-food-andbeverage-advertising-initiative/about-the-initiative/ (accessed December 2016).

9. Frazier WC \& Harris JL (2016) Trends in television food advertising to young people: 2015 update. http://uconnrudd center.org/files/TVAdTrends2016.pdf (accessed December 2016).

10. Powell LM, Schermbeck RM, Szczpka G et al. (2011) Trends in the nutritional content of television food advertisements seen by children in the United States. Arch Pediatr Adolesc Med 165, 1078-1086.

11. Powell LM, Schermbeck RM \& Chaloupka FJ (2013) Nutritional content of food and beverage products in television advertisements seen on children's programming. Child Obes 9, 524-531.

12. Sharma LL, Teret SP \& Brownell KD (2009) The food industry and self-regulation: standards to promote success and to avoid public health failures. Am J Public Health $\mathbf{1 0 0}$, 240-246.

13. World Health Organization (2010) A set of recommendations on the marketing of foods and non-alcoholic beverages to children. http://www.who.int/dietphysicalactivity/ publications/recsmarketing/en/ (accessed August 2016).

14. World Health Organization (2012) A framework for implementing the set of recommendations on the marketing of foods and non-alcoholic beverages to children. http://www. who.int/dietphysicalactivity/MarketingFramework2012.pdf (accessed August 2016).

15. Ofcom (2007) Television advertising of food and drink products to children: final statement. http://stakeholders. ofcom.org.uk/consultations/foodads_new/statement/ (accessed August 2016).

16. Ofcom (2010) HFSS advertising restrictions: final review. http://stakeholders.ofcom.org.uk/market-data-research/other/ tv-research/hfss-final-review/ (accessed August 2016).

17. Boyland EJ, Harold JA, Kirkham TC et al. (2011) The extent of food advertising to children on UK television in 2008. Int J Pediatr Obes 6, 455-461.

18. Adams J, Tyrrell R, Adamson AJ et al. (2012) Effect of restrictions on television food advertising to children on exposure to advertisements for 'less healthy' foods: repeat cross-sectional study. PLoS One 7, e31578.

19. Boyland EJ, Kavanagh-Safran M \& Halford JCG (2015) Exposure to 'healthy' fast food meal bundles in television advertisements promotes liking for fast food but not healthier choices in children. Br J Nutr 113, 1012-1018.

20. Rincon-Gallardo Patino S, Tolentino-Mayo L, Flores Monterrubio EA et al. (2016) Nutritional quality of foods and non-alcoholic beverages advertised on Mexican television according to three nutrient profile models. BMC Public Health 16, 733.

21. World Health Organization (2015) WHO Regional Office for Europe nutrient profile model. http://www.euro.who. int/__data/assets/pdf_file/0005/270716/Europe-nutrientprofile-model-2015-en.pdf?ua=1 (accessed February 2017).
22. Jensen JD \& Ronit K (2015) The EU pledge for responsible marketing of food and beverages to children: implementation in food companies. Eur J Clin Nutr 69, 896-901.

23. Swinburn B, Sacks G, Lobstein T et al. (2008) The 'Sydney Principles' for reducing the commercial promotion of foods and beverages to children. Public Health Nutr 11, 881-886.

24. Potvin Kent M, Dubois L \& Wanless A (2011) Food marketing on children's television in two different policy environments. Int J Pediatr Obes 6, e433-e441.

25. Department of Health (2016) Childhood obesity: a plan for action. https://www.gov.uk/government/publications/childhood-obesity-a-plan-for-action (accessed August 2016).

26. Healthy Eating Research (2015) Recommendations for responsible food marketing to children. http://healthyeatin gresearch.org/research/recommendations-for-responsiblefood-marketing-to-children/ (accessed December 2016).

27. Harris JL, Speers SE, Schwartz MB et al. (2012) US food company branded advergames on the Internet: children's exposure and effects on snack consumption. J Child Media 6, 51-68.

28. US Federal Trade Commission (2010) Interagency Working Group on Food Marketed to Children. Preliminary proposed nutrition principles to guide industry self-regulatory efforts. Request for comments. https://www.ftc.gov/sites/default/ files/documents/public_events/food-marketed-childrenforum-interagency-working-group-proposal/110428food marketproposedguide.pdf (accessed December 2016).

29. Dietz WH (2013) New strategies to improve food marketing to children. Health Aff (Millwood) 32, 1652-1658.

30. House of Commons Health Committee (2016) Childhood obesity - brave and bold action. http://www.publications. parliament.uk/pa/cm201516/cmselect/cmhealth/465/465. pdf (accessed August 2016).

31. Committee of Advertising Practice (2016) Regulatory statement. https://www.asa.org.uk/asset/98337008-FA03-481B-92392CB 3487720A8/ (accessed February 2017).

32. Vergara E \& Henao LA (2016) Chile seeks to fight obesity with new food labelling law. AP The Big Story, 27 June. http:// bigstory.ap.org/article/f9b43cf296a546a09ef1c11d5e3fec01/ chile-seeks-fight-obesity-new-food-labeling-law (accessed January 2017).

33. Trudeau J (2016) Minister of Health Mandate Letter. http://pm. gc.ca/eng/minister-health-mandate-letter (accessed December 2016).

34. European Commission (2008) Questions and answers on food labelling. http://europa.eu/rapid/press-release_MEMO08-64_en.htm (accessed February 2017).

35. Department of Health (2015) Front-of-pack labelling updates. http://www.health.gov.au/internet/main/publishing. nsf/Content/foodsecretariat-front-of-pack-labelling-1 (accessed February 2017).

36. Ministerio de Salud (2015) Sobre Publicidad de los Alimentos. Ley 20869. http://bcn.cl/1vge2 (accessed February 2017).

37. Heart \& Stroke Foundation, Childhood Obesity Foundation \& Stop Marketing to Kids Coalition (2014) The Ottawa Principles. http://stopmarketingtokids.ca/wp-content/uploads/2016/02/ Ottawa-Principles_Jan_2016.pdf (accessed February 2017). 